\title{
KUALITAS KEHIDUPAN KERJA BERPENGARUH TERHADAP KINERJA KARYAWAN DENGAN KOMITMEN ORGANISASIONAL SEBAGAI VARIABEL MEDIASI
}

\author{
I Putu Widnyana Putra ${ }^{1}$ \\ AA. Sagung Kartika Dewi ${ }^{2}$ \\ Fakultas Ekonomi dan Bisnis Universitas Udayana, Bali, Indonesia \\ email: putrawidnyana895@gmail.com; sagungkartika@yahoo.com
}

\begin{abstract}
ABSTRAK
Kinerja karyawan merupakan hasil kerja secara kuantitas maupun kualitas yang dicapai seorang karyawan dalam melaksanakan tugas sesuai dengan tanggung jawab yang telah diberikan. Tujuan penelitian ini adalah untuk mengetahui pengaruh kualitas kehidupan kerja terhadap kinerja karyawan dengan komitmen organisasional sebagai mediasi Penelitian ini dilakukan di Bukit Cili Rafting Karangasem dengan 45 orang sebagai sampel, menggunakan sampel jenuh. Pengumpulan data melalui wawancara dan kuesioner dan dianalisis dengan analisis jalur. Berdasarkan hasil analisis, kualitas kehidupan kerja berpengaruh positif dan signifikan terhadap kinerja karyawan dan komitmen organisasional. Komitmen organisasional berpengaruh positif dan signifikan terhadap kinerja karyawan. Komitmen organisasional sebagai mediasi pengaruh kualitas kehidupan kerja terhadap kinerja karyawan. kualitas kehidupan kerja dan komitmen organisasional secara nyata dapat meningkatkan kinerja karyawan, ketika kualitas kehidupan kerja yang diperoleh oleh karyawan tinggi maka dapat meningkatkan komitmen organisasional menjadi semakin tinggi sehingga berpotensi meningkatkan kinerja karyawan.
\end{abstract}

Kata kunci : kinerja karyawan,kualitas kehidupan kerja,komitmen organisasional

\begin{abstract}
Employee performance is result of work in quantity and quality achieved by an employee in carrying out tasks with the responsibilities that have been given. Purpose of this is to determine the effect of quality of work life on employee performance with organizational commitment as mediator. This research conducted at Bukit Cili Rafting Karangasem with 45 samples, using saturation sampling method. Data collected through interviews and questionnaires and analyzed by path analysis. Based on results, quality of work life has positive and significant effect on employee performance and organizational commitment. Organizational commitment has positive and significant effect on employee performance. Organizational commitment as mediator influences quality of work life on employee performance. Quality of work life and organizational commitment can significantly improve employee performance, when quality of work life obtained by employees is high, it can increase organizational commitment to be higher and thus potentially improve employee performance.

Keywords: employee performance, quality of work life, organizational commitment
\end{abstract}




\section{PENDAHULUAN}

Perkembangan industri pariwisata diera globalisasi ini semakin pesat dikarenakan banyaknya daerah yang mulai mengembangkan potensi wisata. Salah satu dari sekian daerah yang memiliki potensi pariwisata berkelas adalah Bali. Bali merupakan daerah tujuan wisata yang terkenal di dunia. Potensi pariwisata yang dimiliki Bali sangatlah beragam, mulai dari aspek budaya sampai pesona alamnya yang dipadukan dengan ajaran Tri Hita Karana. Keterpaduan yang harmonis berlandaskan Tri Hita Karana menjadikan Bali memiliki daya tarik yang mampu menarik minat wisatawan untuk berkunjung.

Sektor pariwisata di Bali telah tumbuh sedemikian pesat dan dinamis sehingga memunculkan kecendrungan prospektif bisnis pariwisata seperti, munculnya kegiatan wisata berbasis spiritual, wisata alam, wisata olahraga, wisata kuliner dan lain sebagainya. Begitu banyaknya sektor yang tergerak dalam aktivitas pariwisata yang ada di Bali, maka tak heran industri pariwisata telah menjadi tumpuan perekonomian maupun pembangunan daerah Bali. Terkait dengan hal tersebut, perlu diketahui tentang pemahaman wisata alam/ olahraga yang berpotensi untuk terus dikembangkan menjadi wisata minat khusus salah satunya adalah wisata arung jeram (rafting).

Perusahaan dalam penelitian ini adalah Bukit Cili Rafting salah satu perusahaan di Bali yang berkecimpung dalam wisata alam atau olahraga dan telah terdaftar pada Internasional Rafting Federation. Bukit Cili Rafting merupakan salah satu rafting yang melejit namanya di kabupaten karangasem bagian barat setelah BMW Rafting, dengan karyawan yang berjumlah 45 orang. Bukit Cili Rafting berlokasi di Jl. Raya Muncan, Menanga, Rendang, Kabupaten Karangasem, Bali. Berdasarkan observasi dan wawancara terhadap 12 orang karyawan bahwa terindikasi adanya masalah di perusahaan Bukit Cili Rafting baik itu pada kinerja karyawan, kualitas kehidupan kerjanya, dan minimnya komitmen organisasional.

Setiap perusahaan tentu menginginkan agar usahanya berkembang secara berkesinambungan. Maka dari itu perusahaan dituntut memiliki keunggulan dalam segala bidang agar dapat bersaing dengan para pesaing lainnya. Menjadi unggul, tentu perusahaan membutuhkan sumber daya manusia yang berkualitas baik dilihat dari kinerja, kualitas kehidupan kerja maupun komitmen organisasional tersendiri. Manusia merupakan sumber daya yang paling penting dari sebuah organisasi/perusahaan. Manusia memberikan bakat, keahlian, pengetahuan dan pengalaman untuk mencapai tujuan-tujuan perusahaan. Sumber daya manusia merupakan salah satu faktor yang dapat mengembangkan perusahaan kearah kesuksesan. Sumber daya manusia/karyawan senantiasa harus diperhatikan dan dikembangkan untuk menghasilkan kualitas kerja yang sesuai, bahkan melebihi harapan organisasi. Pada dasarnya keberhasilan suatu organisasi akan dibentuk secara langsung dari keberhasilan kinerja karyawan (employee performance).

Kinerja karyawan sangat menentukan keberhasilan pencapaian tujuan organisasi selain itupula kinerja karyawan menjadi suatu potensi dalam melaksanakan setiap tugas dan tanggung jawab yang diberikan organisasi kepadanya. Dengan kinerja karyawan yang baik, maka setiap karyawan dapat menyelesaikan segala tugas yang diberikan oleh organisasi dengan efektif dan efisien sehingga masalah yang terjadi pada organisasi dapat teratasi dengan baik 
.Fenomena yang beberapa kali terjadi selama proses kerja berlangsung di Bukit Cili Rafting adalah complaint dari pihak konsumen. Complaint yang terjadi dilihat dari sisi pelayanan kekonsumen, masih terdapat karyawan yang kurang mengikuti SOP, serta karyawan di Bukit Cili Rafting seringkali menunjukan kinerja yang belum optimal. Kinerja karyawan yang belum optimal tergambarkan dari nilai rata-rata hasil kerja karyawan yang naik turun.:

Tabel 1.

Nilai Rata-rata Hasil Kerja Karyawan Bukit Cili Rafting

\begin{tabular}{rlccccc}
\hline \multirow{2}{*}{ No } & \multicolumn{1}{c}{ Jabatan } & \multicolumn{5}{c}{ Nilai Rata-rata Hasil Kerja } \\
\cline { 2 - 6 } & & $\mathbf{2 0 1 4}$ & $\mathbf{2 0 1 5}$ & $\mathbf{2 0 1 6}$ & $\mathbf{2 0 1 7}$ & $\mathbf{2 0 1 8}$ \\
\hline 1 & Manajer & 86 & 85 & 87 & 88 & 83 \\
2 & Supervisor & 83 & 85 & 86 & 84 & 76 \\
3 & Marketing & 79 & 80 & 81 & 80 & 78 \\
4 & Front Office & 85 & 83 & 85 & 86 & 80 \\
5 & Cashier & 76 & 73 & 77 & 80 & 74 \\
6 & Kitchen & 82 & 79 & 75 & 78 & 75 \\
7 & Guide Service & 80 & 78 & 79 & 78 & 77 \\
8 & Guide & 75 & 74 & 76 & 80 & 75 \\
9 & Driver & 79 & 79 & 77 & 78 & 74 \\
10 & F\&B Service & 77 & 75 & 76 & 74 & 71 \\
11 & Security & 78 & 80 & 77 & 77 & 75 \\
12 & Cleaning Service & 82 & 85 & 81 & 84 & 82 \\
13 & Fittings & 80 & 77 & 80 & 80 & 79 \\
\multicolumn{2}{c}{ Total Nilai Hasil Kerja } & $\mathbf{8 0 , 1}$ & $\mathbf{7 9 , 4}$ & $\mathbf{7 9 , 7}$ & $\mathbf{8 0 , 5}$ & $\mathbf{7 6 , 8}$ \\
\multicolumn{1}{|c}{ Keterangan } & - & Turun & Naik & Naik & Turun \\
\hline
\end{tabular}

Sumber : Bukit Cili Rafting, 2019

Dari data diatas dapat dilihat nilai rata-rata hasil kerja karyawan tiap departemen tidak stabil yaitu terjadinya penurunan dan kenaikan. Nilai rata-rata hasil kerja karyawan terendah terjadi pada tahun 2018 berada dalam kategori skala C yaitu Cukup Baik (70-79), hal ini terjadi karena produktivitas kerja dari setiap karyawannya masih belum optimal sehingga terlihat pada total nilai ratarata hasil kerja karyawan tidak stabil.

Berdasarkan hasil wawancara dengan 12 orang karyawan di Bukit Cili Rafting bahwa, complaint yang telah terindikasi sebagai masalah di Bukit Cili Rafting juga dipengaruhi oleh kualitas kehidupan kerja yang minim. Minimnya kualitas kehidupan kerja diakibatkan dari lingkungan kerja yang tidak kondusif serta kurangnya kepedulian organisasi kepada karyawannya (tidak diberikannya tanggungan keselamatan kerja, pengembangan kompetensi anggota organisasi belum terealisasi dengan baik, serta tidak adanya apresiasi dari organisasi ketika karyawan berkontribusi maksimal dalam pencapaian target perusahaan) 
mengakibatkan karyawan kurang memiliki semangat untuk bekerja secara optimal. Hal tersebut menjadi salah satu pemicu terjadinya complaint.

Sari et al. (2019) pada teori quality of work life dikatakan bahwa para manajer memberikan kesempatan bagi para karyawan untuk mendesain pekerjaan mereka tentang apa yang dibutuhkan dalam menghasilkan produk atau jasa agar mereka dapat bekerja secara efektif. Karena dengan pemberian kualitas kehidupan kerja karyawan yang semakin tinggi, maka kinerja karyawan akan meningkat. Penilitian terdahulu Sari et al. (2019) menemukan bahwa quality work of life $(q w l)$ berpengaruh signifikan terhadap kinerja karyawan. Sementara itu, Tripathy (2017) menemukan bahwa tidak terdapat pengaruh yang signifikan antara quality work of life terhadap kinerja karyawan.

Komitmen memiliki peranan penting terutama pada kinerja seseorang ketika bekerja, hal ini disebabkan oleh adanya komitmen yang menjadi acuan serta dorongan yang membuat mereka lebih bertanggung jawab terhadap kewajibannya (Berberoglu \& Secim, 2015). Sejalan dengan pernyataan diatas apabila dikaitkan dengan masalah yang telah terindikasi di Bukit Cili Rafting, baik itu pada kinerja karyawan maupun kualitas kehidupan kerjanya, menunjukan bahwa kurangnya rasa saling memiliki, baik organisasi kepada karyawannya ataupun sebaliknya (minimnya komitmen organisasional). Minimnya komitmen organisasional merupakan salah satu hal penyebab kinerja karyawan di Bukit Cili Rafting belum optimal.

Komitmen organisasional yang tinggi maka seseorang akan bangga menjadi anggota organisasi dan bekerja dengan maksimal untuk organisasi mereka. Penelitian terdahulu dari Bandula \& Jayatilake (2016), komitmen organisasional berpengaruh negatif terhadap kinerja karyawan. Sedangkan penelitian Planer (2019), menunjukkan bahwa komitmen organisasional berhubungan signifikan positif terhadap kinerja karyawan.

Tujuan dari penelitian ini adalah Untuk Mengetahui Pengaruh Kualitas Kehidupan Kerja terhadap Kinerja Karyawan di Bukit Cili Rafting, Untuk Mengetahui Pengaruh Kualitas Kehidupan Kerja terhadap Komitmen organisasional di Bukit Cili Rafting, Untuk Mengetahui Pengaruh Komitmen organisasional terhadap Kinerja Organisasi di Bukit Cili Rafting dan Untuk Mengetahui Pengaruh Kualitas Kehidupan Kerja terhadap Kinerja Karyawan di Bukit Cili Rafting dengan Komitmen Organisasional Sebagai Mediasi.

Penelitian ini didasari oleh teori pertukaran sosial (Social Exchange Theory), teori pertukaran sosial adalah teori yang paling penting untuk memahami perilaku seseorang di tempat kerja. Seorang pemimpin perusahaan yang mengetahui keinginan karyawan dan dapat menjelaskan apa yang akan diperoleh jika hasil kerjanya sesuai dengan harapan seperti memberikan imbalan yang sebanding dengan kinerjanya, maka karyawan akan berusaha untuk menunjukan kinerjanya yang baik secara maksimal. Teori ini menjelaskan ketika pemimpin mengetahui apa yang masing-masing karyawan butuhkan dalam mencapai kinerja maksimal. Ketika organisasi mengurus karyawan, maka ada hubungan pertukaran sosial yang menjanjikan untuk meningkatkan kinerja (Rabenu \& Rabenu, 2018). Penelitian ini menggunakan teori pertukaran sosial (Social Exchange Theory) untuk memahami 
perilaku karyawan Bukit Cili Rafting dalam kaitannya dengan kinerja karyawan, kualitas kehidupan kerja, dan komitmen organisasional.

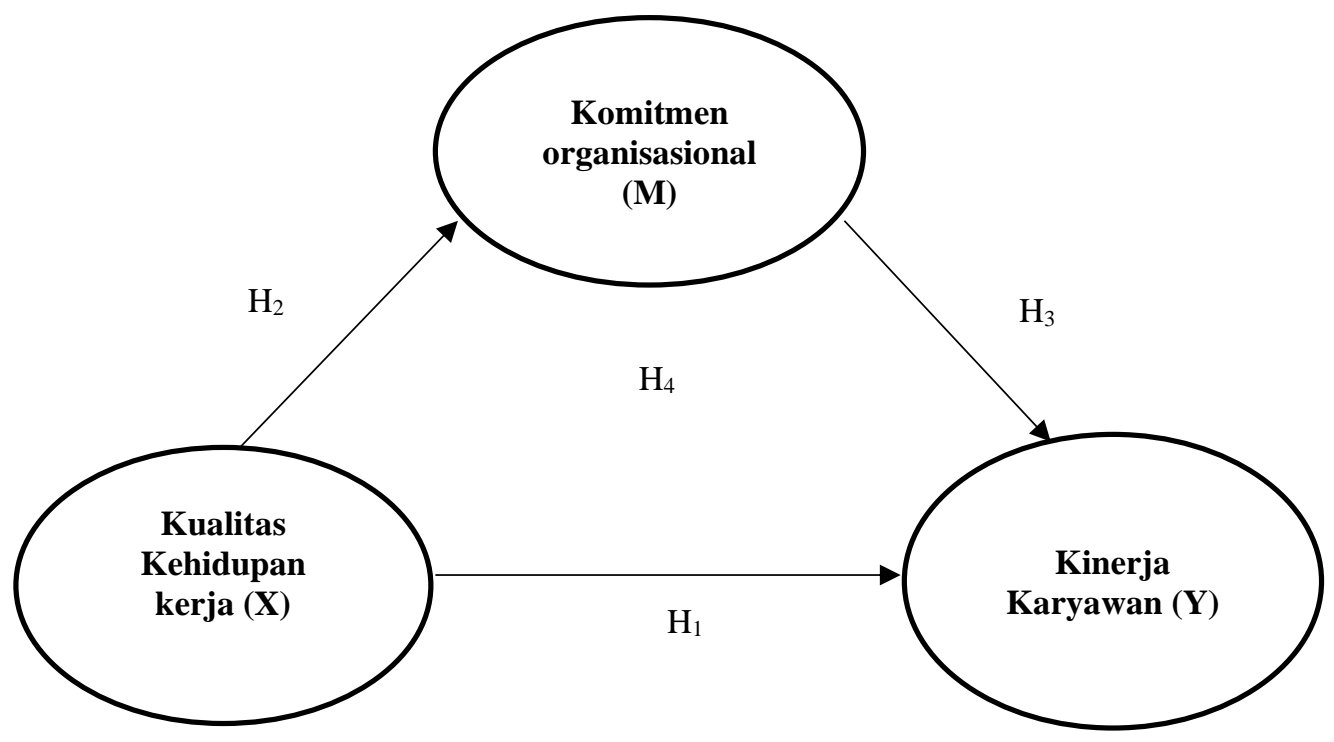

Gambar 1. Kerangka Konseptual

Kualitas kehidupan kerja adalah pemenuhan akan kebutuhan yang berbeda dari setiap karyawan termasuk kebutuhan sosial, harga diri, perealisasian akan setiap keahlian (Velayudhan \& Yameni, 2017). Hasil penelitian Irawati (2015) tentang pengaruh kualitas kehidupan kerja terhadap kinerja pegawai dinas perindustrian dan perdagangan, menyimpulkan hasil penelitiannya bahwa kualitas kehidupan kerja memberikan pengaruh positif terhadap pegawai. Sari et al. (2019) menemukan bahwa quality work of life ( $Q W L)$ berpengaruh signifikan terhadap kinerja karyawan. Rai \& Tripathi (2015) menunjukkan bahwa variabel kualitas kehidupan kerja berpengaruh positif terhadap kinerja karyawan. Indrasari et al. (2018) dalam penelitiannya menyatakan kualitas kehidupan kerja berpengaruh signifikan terhadap kinerja karyawan. Karno \& Indrawati (2016) menyatakan $q w l$ berpengaruh positif dan signifikan terhadap kinerja karyawan. Yuhista et al. (2017) menyatakan kualitas kehidupan kerja berpengaruh signifikan terhadap kinerja karyawan.

$\mathrm{H}_{1}$ : Kualitas kehidupan kerja berpengaruh positif dan signifikan terhadap kinerja karyawan.

Dinamika psikologis dari kualitas kehidupan kerja dengan komitmen organisasional ketika kualitas kehidupan kerja seorang karyawan baik maka komitmen organisasionalnya akan tinggi. Sebaliknya jika kualitas kehidupan kerjanya rendah maka komitmen organisasionalpun akan rendah pula sehingga menyebabkan turnover pada organisasi. Berdasarkan hasil penelitian Selda (2015) yang telah dilakukan maka dapat diketahui kualitas kehidupan kerja berpengaruh positif terhadap komitmen organisasionalonal. Sejalan dengan Bhatnagar \& Soni (2015) menyatakan kualitas kehidupan kerja berpengaruh secara signifikan terhadap komitmen organisasional. 
$\mathrm{H}_{2}$ : Kualitas kehidupan kerja berpengaruh positif dan signifikan terhadap komitmen organisasional.

Komitmen organisasional juga memiliki pengaruh terhadap kinerja karyawan apabila pegawai memiliki komitmen yang tinggi terhadap organisasi tempat mereka bernaung, maka dengan senantiasa pegawai tersebut akan mampu memberikan hasil kerja yang optimal. Komitmen yang kuat dapat membawa dampak positif, antara lain: peningkatan prestasi kerja, motivasi kerja, masa kerja, produktivitas kerja, dan karyawan lebih rajin masuk kerja sehingga mengurangi absensi dan menurunkan turn over. Planer (2019), menunjukkan bahwa komitmen organisasional berhubungan signifikan positif terhadap kinerja karyawan. Nathania (2018) menunjukkan bahwa komitmen organisasional memiliki pengaruh terhadap kinerja karyawan secara parsial maupun simultan. Vipraprastha et al. (2018) menyatakan komitmen organisasional berpengaruh positif signifikan terhadap kinerja karyawan. Asharini \& Irham (2018) menyatakan komitmen organisasional berpengaruh positif terhadap kinerja karyawan.

Fu \& Deshpande (2015) menyatakan komitmen organisasional berpengaruh signifikan terhadap kinerja karyawan. Wahyudi \& Indrawati (2017) menyatakan komitmen organisasional berpengaruh positif dan signifikan terhadap kinerja karyawan. Hogantara \& Sintaasih (2015) menyatakan komitmen organisasional berpengaruh positif dan signifikan terhadap kinerja karyawan. Basalama \& Piartrini (2019) Komitmen organisasional berpengaruh positif dan signifikan terhadap kinerja karyawan. Archita \& Sintaasih (2016) komitmen organisasional secara parsial berpengaruh positif dan signifikan terhadap kinerja karyawan.

$\mathrm{H}_{3}$ : Komitmen organisasional berpengaruh positif dan signifikan terhadap kinerja karyawan.

Komitmen organisasional mendorong karyawan untuk mempertahankan pekerjaannya dan menunjukkan hasil yang seharusnya. Karyawan yang memiliki komitmen yang tinggi terhadap perusahaan cenderung akan menunjukkan kualitas yang baik, lebih totalitas dalam bekerja dan tingkat turnover terhadap perusahaan pun rendah (Amirul et al, 2017). Kualitas kehidupan kerja terhadap kinerja karyawan akan semakin berpengaruh besar atau positif jika memasukan variable komitmen organisasional sebagai variable mediasi, dengan kata lain jika ingin meningkatkan kinerja melalui kualitas kehidupan kerja maka harus menciptakan atau meningkatkan komitmen organisasional terlebih dahulu sebagai peratara $q w l$ terhadap kinerja karyawan (Ramadhoan, 2015). Asharini \& Irham (2018) komitmen organisasional terbukti sebagai variable mediasi antara kualitas kehidupan kerja terhadap kinerja karyawan. Ahadi et al. (2018) Komitmen organisasional memediasi pengaruh kualitas kehidupan kerja terhadap kinerja karyawan. kualitas kehidupan kerja berpengaruh positif dan signifikan terhadap kinerja karyawan yang di mediasi oleh komitmen organisasional (Giarto, 2018).

$\mathrm{H}_{4}$ : Kualitas kehidupan kerja berpengaruh positif signifikan terhadap kinerja karyawan dengan komitmen organisasional sebagai variabel mediasi. 


\section{METODE PENELITIAN}

Penelitian ini menggunakan pendekatan asosiatif. Karena penelitian ini bertujuan untuk menguji pengaruh antar variabel penelitian. Dalam penelitian ini variabel yang di teliti yaitu Kinerja Karyawan (Y) sebagai variabel terikat, Kualitas Kehidupan Kerja (X) sebagai variabel bebas, dan Komitmen organisasional (M) sebagai variabel mediasi. Penelitian ini dilakukan di Bukit Cili Rafting yang beralamat di Jl. Raya Muncan, Menanga, Rendang, Kabupaten Karangasem, Bali.

Kinerja Karyawan dalam penelitian ini merupakan hasil yang dicapai seorang karyawan dalam melaksanakan tugas dan tanggung jawab yang diberikan kepadanya guna mewujudkan sasaran, tujuan, visi dan misi organisasi. Kualitas kehidupan kerja dalam penelitian ini merupakan sebuah proses dimana organisasi memberikan respon pada kebutuhan karyawan, agar karyawan merasa aman, nyaman, tentram, serta diberikan kesempatan bagi karyawan untuk mengembangkan potensinya didalam suatu organisasi. Komitmen organisasional dalam penelitian ini adalah keterkaitan seorang karyawan dengan organisasi ataupun sebaliknya keinginan organisasi untuk mempertahankan serta mensejahterkan anggotanya guna terealisasinya tujuan yang telah ditetapkan.

Data kualitatif pada penelitian ini berupa pendapat dari responden yang meliputi variabel bebas dan terikat. Data kuantitatif pada penelitian ini berupa data kualitatif yang di angkakan dan dapat dihitung dengan satuan hitung. Didalam penelitian ini adalah data jumlah karyawan dan data hasil kuesioner. Sumber data primer berupa data yang dapat diperoleh secara langsung dari Bukit Cili Rafting dengan menggunakan kuesioner dan wawancara, dimana dalam wawancara peneliti mendapat jawaban langsung dari responden dan melalui kuesioner responden memberikan skor pada variabel- variabel penelitian dalam kuesioner. Sumber data sekunder berupa data yang sudah dalam bentuk jadi atau dapat dikatakan data yang sudah tersedia di Bukit Cili Rafting, contohnya seperti data Jumlah karyawan dan data-data perusahaan yang diperlukan dalam penelitian ini.

Populasi dan sampel dalam penelitian ini adalah seluruh karyawan di Bukit Cili Rafting yang berjumlah 45 orang. Metode pengambilan sampe menggunakan sampling jenuh. Metode pengumpulan data yang digunakan adalah wawancara , kuesioner dan observasi. Wawancara merupakan metode pengumpulan data dengan tanya jawab secara langsung dengan manajer dan karyawan Bukit Cili Rafting. Pertanyaan dalam wawancara meliputi permasalahan ataupun keluhan pegawai yang berkaitan dengan Job description, kinerja karyawan, kualitas kehidupan kerja, komitmen organisasional di Bukit Cili Rafting. Kuesioner dapat berupa pertanyaan/pernyataan tertutup atau terbuka dapat diberikan kepada responden secara langsung atau dikirim melalui pos atau internet. Kuesioner penelitian ini diukur dengan menggunakan skala Likert, yaitu pilihan jawaban responden diberi nilai dengan skala lima poin pada table. Metode Observasi partisipan merupakan mengamati secara langsung bagaimana kinerja karyawan, kualitas kehidupan kerja, dan komitmen organisasional di Bukit Cili Rafting.

\section{HASIL DAN PEMBAHASAN}


Bukit Cili Rafting merupakan salah satu perusahaan yang bergerak dalam sektor industri pariwisata yang berlokasi di Jl. Raya Muncan, Menanga, Rendang, Kabupaten Karangasem, Bali. Bukit Cili Rafting dibangun dengan semangat kebersamaan pada tahun 2010 dalam rangka pengembangan sektor penunjang kepariwisataan yang berada di Bali khususnya di wilayah Karangasem agar terjadi pemerataan di seluruh Bali dengan tujuan dasar pemberdayaan masyarakat lokal sesuai kemampuan dan profesionalismenya. Bukit Cili Rafting dengan motto 'Pelayanan Terbaik Harga bersaing" merupakan salah satu rafting yang melejit namanya di kabupaten Karangasem bagian barat dan telah terdaftar pada Internasional Rafting Federation (IRF).

Data karakteristik responden adalah data responden yang dikumpulkan untuk mengetahui profil responden penelitian. Berdasarkan hasil penelitian yang dilakukan terhadap karyawan di Bukit Cili Rafting Karangasem dapat diketahui karakteristik respondennya meliputi jenis kelamin, usia dan pendidikan terakhir yang dijelaskan pada Tabel 2 .

Tabel 2.

Karakteristik Responden

\begin{tabular}{|c|c|c|c|c|}
\hline No & Variabel & Klasifikasi & $\begin{array}{l}\text { Jumlah } \\
\text { (orang) }\end{array}$ & $\begin{array}{c}\text { Persentase } \\
(\%)\end{array}$ \\
\hline \multirow{4}{*}{1} & \multirow{2}{*}{ Jenis Kelamin } & Laki - Laki & 37 & 82.22 \\
\hline & & Perempuan & 8 & 17.78 \\
\hline & & Jumlah & 45 & 100 \\
\hline & & 17-20 Tahun & 17 & 37.78 \\
\hline \multirow[t]{4}{*}{2} & Usia & 21-30 Tahun & 18 & 40.00 \\
\hline & & $>30$ Tahun & 10 & 22.22 \\
\hline & \multicolumn{2}{|r|}{ Jumlah } & 45 & 100 \\
\hline & \multirow{4}{*}{$\begin{array}{l}\text { Pendidikan } \\
\text { terakhir }\end{array}$} & SMA & 16 & 35.56 \\
\hline \multirow[t]{3}{*}{3} & & Diploma & 18 & 40.00 \\
\hline & & S1 & 11 & 24.44 \\
\hline & & Jumlah & 45 & 100 \\
\hline \multirow[t]{3}{*}{4} & Masa Kerja & 1-5 Tahun & 32 & 71,11 \\
\hline & & $>5$ Tahun & 13 & 28,89 \\
\hline & & Jumlah & 45 & 100 \\
\hline
\end{tabular}

Sumber : Data diolah, 2019

Jumlah karyawan di Bukit Cili Rafting Karangasem yang di jadikan sampel sebanyak 45 orang. Jika di lihat dari jenis kelamin, jenis kelamin laki-laki mendominasi dalam penelitian ini dengan presentase sebesar 82.22 persen dikarenakan ruang lingkup pekerjaan di Bukit Cili Rafting dominan mengarah pada kekuatan fisik laki-laki. Jika di lihat dari usia, yang memiliki usia 21-30 tahun mendominasi dengan presentase sebesar 40.00 persen sebab usia 21-30 masa seseorang produktif bekerja melihat bidang serta ruang lingkup pekerjaan di Bukit Cili Rafting yang lebih mengarah pada kemampuan fisik. Jika dilihat dari tingkat pendidikan, tingkat pendiddikan terakhir diploma yang mendominasi dengan persentase sebesar 40.00 persen karena perusahaan telah menentukan hal tersebut 
sesuai dengan bidang pekerjaan yang ada di Bukit Cili Rafting. Jika dilihat dari masa kerja, masa kerja 1-5 tahun mendominasi dengan persentase 71,11 persen dikarenakan dominan karyawan Bukit Cili Rafting sekarang ini baru bergabung kisaran tahun 2015.

Seluruh instrumen variabel penelitian berupa Kualitas kehidupan kerja, komitmen organisasional dan Kinerja Karyawan telah memenuhi syarat uji validitas yang dimana nilai skor total Pearson Correlation masing-masing instrumen berada diatas 0,30 dan mimiliki nilai signifikansi yang lebih kecil dari $5 \%(0,05)$, maka instrumen layak digunakan menjadi alat ukur variabel-variabel tersebut.

Tabel 3.

Hasil Uji Validitas

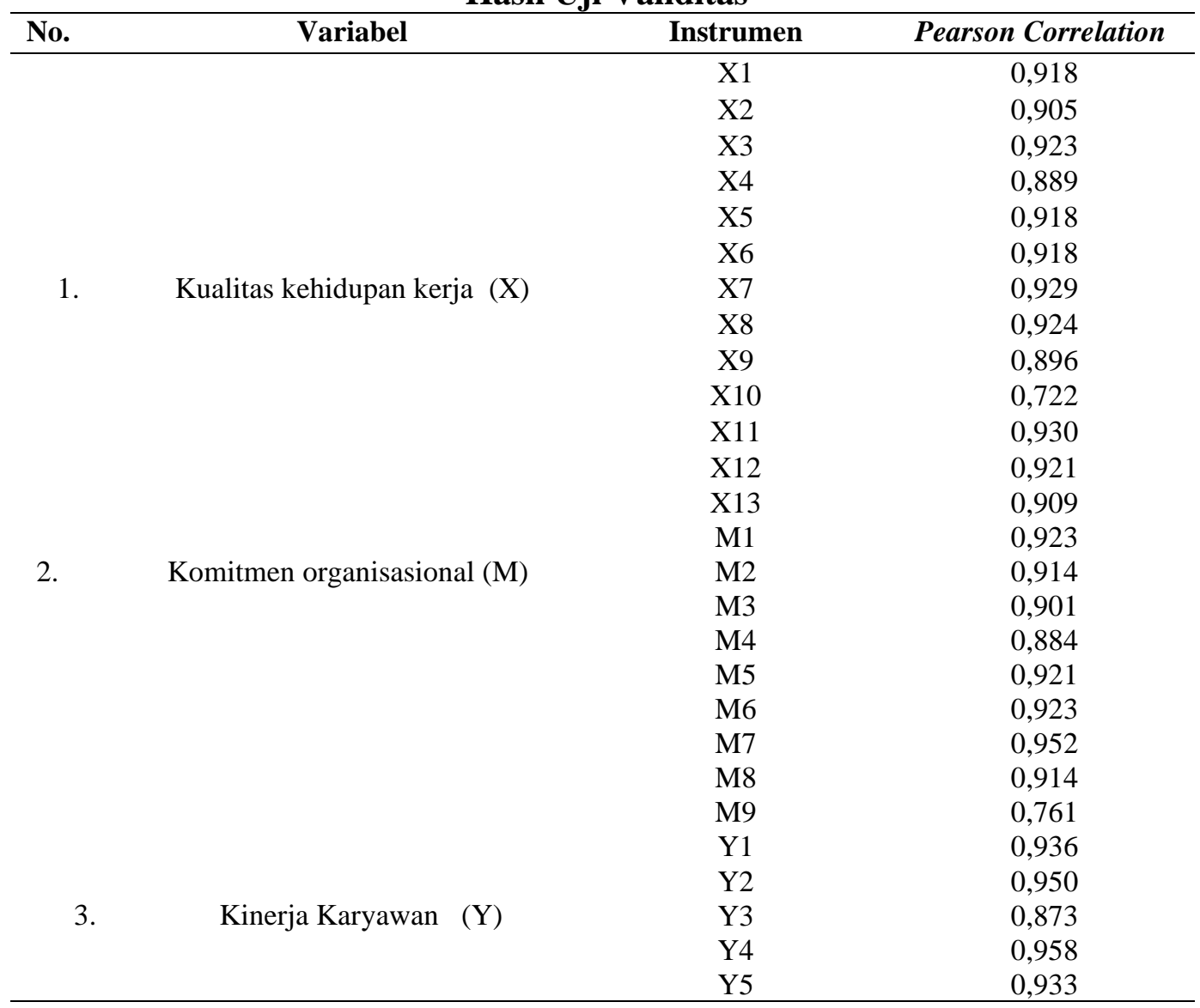

Sumber : Data diolah, 2019

Uji reliabilitas pada masing-masing variabel berada pada titik diatas 0,60 yang ditunjukkan pada hasil Cronbach's Alpha, maka dapat dikatakan seluruh instrumen telah memenuhi syarat reliabilitas. 
Tabel 4.

Uji Reliabilitas

\begin{tabular}{clc}
\hline No. & \multicolumn{1}{c}{ Variabel } & Cronbach's Alpha \\
\hline 1. & Kualitas kehidupan kerja (X) & 0,980 \\
2. & Komitmen organisasional (M) & 0,969 \\
3. & Kinerja Karyawan (Y) & 0,961 \\
\hline
\end{tabular}

Sumber: Data diolah, 2019

Tabel 5.

Deskripsi Jawaban Responden Terhadap Kualitas Kehidupan Kerja

\begin{tabular}{|c|c|c|c|c|c|c|c|c|c|}
\hline \multirow[t]{2}{*}{ No } & \multirow[t]{2}{*}{ Pernyataan } & \multicolumn{5}{|c|}{$\begin{array}{c}\text { Proporsi Jawaban } \\
\text { Responden } \\
\text { (orang) }\end{array}$} & \multirow[t]{2}{*}{ Jumlah } & \multirow[t]{2}{*}{$\begin{array}{l}\text { Rata- } \\
\text { rata }\end{array}$} & \multirow[t]{2}{*}{ Kriteria } \\
\hline & & 1 & 2 & 3 & 4 & 5 & & & \\
\hline 1 & $\begin{array}{l}\text { Saya sering dilibatkan } \\
\text { dalam proses pengambilan } \\
\text { keputusan oleh organisasi }\end{array}$ & 2 & 8 & 10 & 20 & 5 & 153 & 3.40 & Sedang \\
\hline 2 & $\begin{array}{l}\text { Saya mendapat dampak } \\
\text { positif dari partisipasi } \\
\text { yang saya berikan }\end{array}$ & 4 & 7 & 7 & 23 & 4 & 151 & 3.36 & Tinggi \\
\hline 3 & $\begin{array}{l}\text { Organisasi sering } \\
\text { mendorong saya untuk } \\
\text { memberikan pendapat }\end{array}$ & 3 & 6 & 8 & 20 & 8 & 159 & 3.53 & Sedang \\
\hline 4 & $\begin{array}{l}\text { Organisasi selalu } \\
\text { memberikan } \\
\text { pengembangan karir bagi } \\
\text { setiap karyawan }\end{array}$ & 5 & 5 & 14 & 12 & 9 & 150 & 3.33 & Sedang \\
\hline 5 & $\begin{array}{lr}\text { Organisasi } & \text { memberikan } \\
\text { apresiasi } & \text { terhadap } \\
\text { kemampuan } & \text { karyawan }\end{array}$ & 1 & 9 & 10 & 20 & 5 & 154 & 3.42 & Tinggi \\
\hline 6 & $\begin{array}{l}\text { Organisasi membimbing } \\
\text { dengan baik }\end{array}$ & 1 & 9 & 10 & 20 & 5 & 154 & 3.42 & Tinggi \\
\hline 7 & $\begin{array}{l}\text { Gaji saya sesuai standar } \\
\text { penggajian yang berlaku }\end{array}$ & 6 & 5 & 6 & 23 & 5 & 151 & 3.36 & Sedang \\
\hline 8 & $\begin{array}{l}\text { Organisasi memberikan } \\
\text { gaji tepat waktu }\end{array}$ & 4 & 5 & 8 & 20 & 8 & 158 & 3.51 & Tinggi \\
\hline 9 & $\begin{array}{l}\text { Saya mendapatkan bonus } \\
\text { jika menyelesaikan } \\
\text { pekerjaan tepat waktu }\end{array}$ & 4 & 6 & 13 & 13 & 9 & 152 & 3.38 & Sedang \\
\hline 10 & $\begin{array}{l}\text { Organisasi memberikan } \\
\text { tunjangan sosial }\end{array}$ & 0 & 9 & 10 & 19 & 7 & 159 & 3.53 & Tinggi \\
\hline 11 & $\begin{array}{l}\text { Suasana kerja membuat } \\
\text { saya nyaman bekerja }\end{array}$ & 4 & 7 & 6 & 24 & 4 & 152 & 3.38 & Sedang \\
\hline 12 & $\begin{array}{l}\text { Hubungan kerja saya } \\
\text { dengan sesama karyawan } \\
\text { membuat saya nyaman }\end{array}$ & 2 & 7 & 8 & 20 & 8 & 160 & 3.56 & Tinggi \\
\hline 13 & $\begin{array}{l}\text { Peraturan yang ditetapkan } \\
\text { pada oraganisasi tempat } \\
\text { saya bekerja membuat } \\
\text { saya aman dalam bekerja } \\
\text { Rata-rata }\end{array}$ & 5 & 5 & 13 & 13 & 9 & 151 & 3.36 & Sedang \\
\hline
\end{tabular}


Sumber : Data diolah, 2019

Variabel Kualitas kehidupan kerja yang memiliki rata-rata terendah adalah pernyataan "Organisasi selalu memberikan pengembangan karir bagi setiap karyawan", diperoleh nilai rata-rata sebesar 3,33 yang masuk kriteria Sedang, tetapi memiliki nilai rata-rata yang rendah dibandingkan dengan pernyataan yang lainnya ini berarti secara umum responden menganggap Organisasi belum selalu memberikan pengembangan karir bagi setiap karyawan. Variabel Kualitas kehidupan kerja yang memiliki rata-rata tertinggi adalah pernyataan "Hubungan kerja saya dengan sesama karyawan membuat saya nyaman dalam bekerja", diperoleh nilai rata-rata sebesar 3,56 yang masuk kriteria tinggi, ini berarti secara umum hubungan kerja karyawan dengan sesama rekan kerja membuat karyawan nyaman dalam bekerja.

Tabel 6.

Deskripsi Jawaban Responden Terhadap Komitmen Organisasional

\begin{tabular}{|c|c|c|c|c|c|c|c|c|c|}
\hline \multirow{2}{*}{ No } & \multirow{2}{*}{ Pernyataan } & \multicolumn{5}{|c|}{$\begin{array}{c}\text { Proporsi Jawaban } \\
\text { Responden }\end{array}$} & \multirow{2}{*}{ Jumlah } & \multirow{2}{*}{ Rata-rata } & \multirow{2}{*}{ Kriteria } \\
\hline & & 1 & 2 & 3 & 4 & 5 & & & \\
\hline 1 & $\begin{array}{l}\text { Saya merasa ikut } \\
\text { memiliki Organisasi }\end{array}$ & 4 & 4 & 7 & 26 & 4 & 157 & 3.49 & Tinggi \\
\hline 2 & $\begin{array}{l}\text { Saya merasa terikat } \\
\text { secara emosional } \\
\text { dengan organisasi ini }\end{array}$ & 4 & 6 & 9 & 20 & 6 & 153 & 3.40 & Sedang \\
\hline 3 & bagian dari organisasi & 2 & 8 & 11 & 18 & 6 & 153 & 3.40 & Sedang \\
\hline 4 & $\begin{array}{l}\text { Saya merasa dengan } \\
\text { bekerja di organisasi } \\
\text { ini merupakan } \\
\text { kesempatan terbaik }\end{array}$ & 4 & 6 & 13 & 15 & 7 & 150 & 3.33 & Sedang \\
\hline 5 & $\begin{array}{l}\text { Saya merasa rugi jika } \\
\text { keluar dari organisasi }\end{array}$ & 3 & 5 & 7 & 27 & 3 & 157 & 3.49 & Tinggi \\
\hline 6 & $\begin{array}{lr}\begin{array}{l}\text { Saya merasa } \\
\text { bekerja }\end{array} & \text { jika } \\
\text { organisasi } & \text { ini } \\
\text { merupakan } & \text { suatu } \\
\text { kebutuhan } & \end{array}$ & 3 & 7 & 6 & 22 & 7 & 158 & 3.51 & Tinggi \\
\hline 7 & $\begin{array}{l}\text { Saya masih ingin } \\
\text { bertahan di organisasi }\end{array}$ & 2 & 8 & 9 & 18 & 8 & 157 & 3.49 & Tinggi \\
\hline 8 & $\begin{array}{l}\text { Saya ingin ingin } \\
\text { menghabiskan sisa } \\
\text { karir di organisasi ini }\end{array}$ & 3 & 7 & 10 & 17 & 8 & 155 & 3.44 & Tinggi \\
\hline 9 & $\begin{array}{lr}\text { Saya tidak tertarik } \\
\text { pada } & \text { tawaran } \\
\text { pekerjaan } & \text { dari } \\
\text { organisasi lain yang } \\
\text { mungkin lebih baik } \\
\text { dari organisasi ini }\end{array}$ & 4 & 7 & 13 & 14 & 7 & 148 & 3.29 & Sedang \\
\hline \multicolumn{7}{|c|}{ Rata-rata } & & $\mathbf{3 , 4 3}$ & Tinggi \\
\hline
\end{tabular}


Variabel komitmen organisasional yang memiliki rata-rata terendah adalah pernyataan "Saya tidak tertarik pada tawaran pekerjaan dari organisasi lain yang mungkin lebih baik dari organisasi ini", diperoleh nilai rata-rata sebesar 3,29 yang masuk kriteria sedang, tetapi memiliki nilai rata-rata yang rendah dibandingkan dengan pernyataan yang lainnya ini berarti secara umum responden menganggap tertarik pada tawaran pekerjaan dari organisasi lain yang mungkin lebih baik dari organisasi ini. Variabel komitmen organisasional yang memiliki rata-rata tertinggi adalah pernyataan "Saya merasa jika bekerja pada organisasi ini merupakan suatu kebutuhan", diperoleh nilai rata-rata sebesar 3,51 yang masuk kriteria tinggi, ini berarti secara umum responden merasa jika bekerja pada organisasi ini merupakan suatu kebutuhan

Tabel 7.

Deskripsi Jawaban Responden Terhadap Kinerja Karyawan

\begin{tabular}{|c|c|c|c|c|c|c|c|c|c|}
\hline \multirow{3}{*}{ No } & \multirow{3}{*}{ Pernyataan } & \multirow{2}{*}{\multicolumn{5}{|c|}{$\begin{array}{l}\text { Proporsi Jawaban } \\
\text { Responden } \\
\text { (orang) }\end{array}$}} & \multirow{3}{*}{ Jumlah } & \multirow{3}{*}{$\begin{array}{c}\text { Rata- } \\
\text { rata }\end{array}$} & \multirow{3}{*}{ Kriteria } \\
\hline & & & & & & & & & \\
\hline & & 1 & 2 & 3 & 4 & 5 & & & \\
\hline 1 & $\begin{array}{l}\text { Saya dapat memenuhi } \\
\text { standar kerja yang } \\
\text { ditentukan }\end{array}$ & 5 & 6 & 8 & 17 & 9 & 154 & 3.42 & Tinggi \\
\hline 2 & $\begin{array}{l}\text { Saya menyelesaikan } \\
\text { tugas-tugas yang } \\
\text { diberikan sesuai dengan } \\
\text { target yang telah } \\
\text { ditentukan }\end{array}$ & 4 & 8 & 7 & 19 & 7 & 152 & 3.38 & Sedang \\
\hline 3 & $\begin{array}{l}\text { Saya dapat } \\
\text { mengerjakan pekerjaan } \\
\text { dengan baik tanpa } \\
\text { banyak instruksi dari } \\
\text { atasan }\end{array}$ & 2 & 9 & 13 & 14 & 7 & 150 & 3.33 & Sedang \\
\hline 4 & $\begin{array}{l}\text { Saya mengerjakan } \\
\text { tugas yang diberikan } \\
\text { oleh organisasi dengan } \\
\text { tepat waktu }\end{array}$ & 6 & 7 & 8 & 11 & 13 & 153 & 3.40 & Sedang \\
\hline 5 & $\begin{array}{l}\text { Hubungan kerja saya } \\
\text { dengan atasan maupun } \\
\text { rekan kerja terjalin } \\
\text { baik }\end{array}$ & 6 & 5 & 8 & 18 & 8 & 152 & 3.38 & Sedang \\
\hline \multicolumn{8}{|c|}{ Rata-rata } & 3,38 & Sedang \\
\hline
\end{tabular}

Sumber: Data diolah, 2019

Variabel Kinerja Karyawan yang memiliki rata-rata terendah adalah pernyataan "Saya dapat mengerjakan pekerjaan dengan baik tanpa banyak instruksi dari atasan", diperoleh nilai rata-rata sebesar 3,33 yang masuk kriteria sedang, tetapi memiliki nilai rata-rata yang rendah dibandingkan dengan pernyataan yang lainnya ini berarti secara umum karyawan belum dapat mengerjakan pekerjaan dengan baik tanpa banyak instruksi dari atasan. Variabel Kinerja Karyawan yang memiliki rata-rata tertinggi adalah pernyataan "Saya dapat memenuhi standar kerja yang ditentukan", diperoleh nilai rata-rata sebesar 
3,42 yang masuk kriteria tinggi, ini berarti secara umum responden dapat memenuhi standar kerja yang ditentukan.

Tabel 8.

Hasil Analisis Jalur Pada Struktur 1

\begin{tabular}{|c|c|c|c|c|c|c|}
\hline \multirow{2}{*}{\multicolumn{2}{|c|}{ Model }} & \multicolumn{2}{|c|}{ UnstandardiMed Coefficients } & \multirow{2}{*}{$\begin{array}{c}\begin{array}{c}\text { StandardiMed } \\
\text { Coefficients }\end{array} \\
\text { Beta }\end{array}$} & \multirow[t]{2}{*}{$\mathbf{T}$} & \multirow[t]{2}{*}{ Sig. } \\
\hline & & B & Std. Error & & & \\
\hline (Constant & & 1.449 & 0.385 & & 3.763 & 0.001 \\
\hline $\begin{array}{l}\text { Kualitas } \\
\text { kerja } \\
\mathrm{R}^{2}\end{array}$ & $\begin{array}{l}\text { kehidupan } \\
: 0,416\end{array}$ & 0.597 & 0.108 & 0.645 & 5.538 & 0.000 \\
\hline
\end{tabular}

Variabel Kualitas kehidupan kerja memiliki koefisien sebesar 0,645 berarti Kualitas kehidupan kerja memiliki pengaruh positif terhadap komitmen organisasional, ini diartikan apabila Kualitas kehidupan kerja meningkat maka komitmen organisasional akan meningkat sebesar 0,645.

Tabel 9.

Hasil Analisis Jalur Pada Struktur 2

\begin{tabular}{|c|c|c|c|c|c|}
\hline \multirow{2}{*}{ Model } & \multicolumn{2}{|c|}{$\begin{array}{c}\text { UnstandardiMed } \\
\text { Coefficients }\end{array}$} & \multirow{2}{*}{$\begin{array}{c}\begin{array}{c}\text { StandardiMed } \\
\text { Coefficients }\end{array} \\
\text { Beta } \\
\end{array}$} & \multirow[t]{2}{*}{$\mathbf{T}$} & \multirow[t]{2}{*}{ Sig. } \\
\hline & $\mathrm{B}$ & Std. Error & & & \\
\hline (Constant) & -0.113 & 0.417 & & -0.270 & 0.788 \\
\hline $\begin{array}{l}\text { Kualitas kehidupan } \\
\text { kerja }\end{array}$ & 0.411 & 0.133 & 0.371 & 3.096 & 0.003 \\
\hline $\begin{array}{l}\text { Komitmen } \\
\text { organisasional }\end{array}$ & 0.613 & 0.143 & 0.513 & 4.278 & 0.000 \\
\hline$: 0.647$ & & & & & \\
\hline
\end{tabular}

Sumber : Data diolah, 2019

Variabel Kualitas kehidupan kerja memiliki koefisien sebesar 0,371 berarti Kualitas kehidupan kerja memiliki pengaruh positif terhadap Kinerja Karyawan, ini diartikan apabila Kualitas kehidupan kerja meningkat maka Kinerja Karyawan akan meningkat sebesar 0,371. Variabel komitmen organisasional memiliki koefisien sebesar 0,513 berarti komitmen organisasional memiliki pengaruh positif terhadap Kinerja Karyawan ini diartikan apabila komitmen organisasional meningkat maka Kinerja Karyawan akan meningkat sebesar 0,513. Pada perhitungan nilai koefisien determinasi total didapatkan sebesar 0,794, maka kesimpulannya adalah 79,4\% variabel Kinerja Karyawan di Bukit Cili Rafting Karangasem dipengaruhi oleh Kualitas kehidupan kerja, dan komitmen organisasional, sedangkan sisanya 20,6\% dipengaruhi oleh faktor lain yang tidak dimasukkan dalam model penelitian atau diluar model penelitian. 
Tabel 10.

Uji Normalitas (One-Sample Kolmogorov-Smirnov)

\begin{tabular}{cc}
\hline Persamaan & Kolmogorov-Smirnov M \\
\hline Substruktur 1 & 0,544 \\
Substruktur 2 & 0,963 \\
\hline
\end{tabular}

Sumber : Data diolah, 2019

Berdasarkan uji normalitas dengan menggunakan One-Sample KolmogorovSmirnov Test menunjukkan bahwa besarnya nilai Kolmogorov-Smirnov adalah sebesar 0,544 dan 0,963 sehingga dapat disimpulkan bahwa model memenuhi asumsi normalitas

Tabel 11.

Uji Multikolinieritas (Tolerance dan Variance Inflation Factor)

\begin{tabular}{clcc}
\hline \multirow{2}{*}{ Model } & \multicolumn{2}{c}{ Collinearity Statistics } \\
\cline { 3 - 4 } Substruktur2 & $\begin{array}{l}\text { Kualitas kehidupan } \\
\text { kerja } \\
\text { Komitmen } \\
\text { organisasional }\end{array}$ & 0.584 & \multicolumn{1}{c}{ Tolerance } \\
\hline
\end{tabular}

Sumber : Data diolah, 2019

Tidak terdapat variabel bebas yang memiliki nilai tolerance kurang dari 0,10 dan juga tidak ada variabel bebas yang memiliki nilai VIF lebih dari 10. Maka dari pada itu model regresi bebas dari gejala multikoleniaritas.

Tabel 12.

Uji Heteroskedastisitas (Uji Glesjer) Coefficients(a)

\begin{tabular}{clcc}
\hline Persamaan & \multicolumn{1}{c}{ Model } & T & Sig. \\
\hline Substruktur1 & Kualitas kehidupan kerja & -0.739 & 0.464 \\
& Kualitas kehidupan kerja & -1.493 & 0.143 \\
Substruktur 2 & Komitmen organisasional & 1.428 & 0.161 \\
\hline
\end{tabular}

Sumber : Data diolah, 2019

Masing - masing model memiliki nilai signifikansi lebih besar dari 5\%. Hal ini menunjukkan bahwa variabel bebas yang digunakan pada penelitian ini tidak berpengaruh secara signifikan terhadap variabel terikatnya yaitu absolute error, maka dari itu, penelitian ini bebas dari gejala heteroskedastisitas.

Tabel 13.

Pengaruh Langsung, Pengaruh Tidak Langsung Kualitas kehidupan kerja (X), Terhadap Komitmen organisasional (M) dan Kinerja Karyawan (Y).

\begin{tabular}{cccc}
\hline Pengaruh variabel & $\begin{array}{c}\text { Pengaruh } \\
\text { langsung }\end{array}$ & $\begin{array}{c}\text { Pengaruh tidak } \\
\text { langsung melalui } \mathbf{M}\end{array}$ & $\begin{array}{c}\text { Pengaruh } \\
\text { Total }\end{array}$ \\
\hline $\mathrm{X} \rightarrow \mathrm{M}$ & 0,645 & & 0,645 \\
$\mathrm{M} \rightarrow \mathrm{Y}$ & 0,513 & 0,331 & 0,513 \\
$\mathrm{X} \rightarrow \mathrm{Y}$ & 0,371 & 0,702 \\
\hline
\end{tabular}

Sumber: Data diolah, 2019 
Pada penelitian yang dilakukan di Perusahaan Bukit Cili Rafting Karangasem tentang pengaruh Kualitas kehidupan kerja terhadap komitmen organisasional, maka didapatkan hasil Kualitas kehidupan kerja memiliki pengaruh langsung terhadap komitmen organisasional sebesar 0,645. Pada penelitian yang dilakukan di Perusahaan Bukit Cili Rafting Karangasem tentang pengaruh komitmen organisasional terhadap Kinerja Karyawan, maka didapatkan hasil komitmen organisasional memiliki pengaruh langsung terhadap Kinerja Karyawan sebesar 0,513 .

Pada penelitian yang dilakukan di Perusahaan Bukit Cili Rafting Karangasem tentang pengaruh kualitas kehidupan kerja terhadap kinerja karyawan, maka didapatkan hasil Kualitas kehidupan kerja memiliki pengaruh langsung terhadap kinerja karyawan sebesar 0,371 Pada penelitian yang dilakukan di Bukit Cili Rafting Karangasem tentang peran komitmen organisasional dalam memediasi pengaruh kualitas kehidupan kerja terhadap kinerja karyawan, maka didapatkan hasil bahwa Kualitas kehidupan kerja memiliki pengaruh langsung dan tidak langsung melalui komitmen organisasional terhadap kinerja karyawan dengan nilai koefisien masing-masing sebesar 0,371 dan 0,331, sehingga besaran pengaruh totalnya adalah 0,702 .

Kualitas kehidupan kerja memiliki nilai Beta sebesar 0,371 dan nilai Sig. sebesar 0,003, maka dapat dikatakan $\mathrm{H}_{\mathrm{a}}$ diterima karena nilai Sig. 0,003<0,05. Kesimpulannya adalah Kualitas kehidupan kerja berpengaruh positif dan signifikan terhadap Kinerja Karyawan dengan kata lain semakin meningkat Kualitas kehidupan kerja maka Kinerja Karyawan di Bukit Cili Rafting Karangasem akan semakin meningkat. Sehingga hipotesis pertama diterima. Hal ini sejalan dengan hasil penelitian yang dilakukan oleh Sari et al. (2019) menemukan bahwa quality work of life $(Q W L)$ berpengaruh signifikan terhadap kinerja karyawan. Rai \& Tripathi (2015) menunjukkan bahwa variabel kualitas kualitas kehidupan kerja berpengaruh positif terhadap kinerja karyawan. Indrasari et al. (2018) dalam penelitiannya menyatakan kualitas kualitas kehidupan kerja berpengaruh signifikan terhadap kinerja karyawan. Karno \& Indrawati (2016) menyatakan $q w l$ berpengaruh positif dan signifikan terhadap kinerja karyawan. Yuhista et al. (2017) menyatakan kualitas kualitas kehidupan kerja berpengaruh signifikan terhadap kinerja karyawan.

Kualitas kehidupan kerja memiliki nilai Beta sebesar 0,645 dan nilai Sig. sebesar 0,000, maka dapat dikatakan $\mathrm{H}_{\mathrm{a}}$ diterima karena nilai Sig. 0,000<0,05. Kesimpulannya adalah bahwa Kualitas kehidupan kerja memiliki pengaruh positif dan signifikan terhadap komitmen organisasional, dengan kata lain semakin meningkat Kualitas kehidupan kerja di Bukit Cili Rafting Karangasem, maka semakin meningkat komitmen organisasional di Bukit Cili Rafting Karangasem. Sehingga hipotesis kedua diterima. Hal ini sejalan dengan hasil penelitian yang dilakukan olehBhatnagar \& Soni (2015) menyatakan kualitas kualitas kehidupan kerja berpengaruh secara signifikan terhadap komitmen organisasional.

Komitmen organisasional memiliki nilai Beta sebesar 0,513 dan nilai Sig. sebesar 0.000, maka dapat dikatakan $\mathrm{H}_{\mathrm{a}}$ diterima karena nilai Sig. $0.000<0,05$. Kesimpulannya adalah bahwa Komitmen organisasional memiliki pengaruh 
positif dan signifikan terhadap Kinerja Karyawan, dengan kata lain apabila komitmen organisasional meningkat maka Kinerja Karyawan di Bukit Cili Rafting Karangasem. akan semakin meningkat. Sehingga hipotesis ketiga diterima. Hasil penelitian ini sesuai dengan penelitian yang dilakukan oleh Vipraprastha et al. (2018), Asharini \& Irham (2018), Fu \& Deshpande (2015), Wahyudi \& Indrawati (2017), Hogantara \& Sintaasih (2015), Basalama \& Piartrini (2019) dan Archita \& Sintaasih (2016)

Berdasarkan hasil Uji Sobel menunjukkan bahwa hasil tabulasi $\mathrm{Z}=$ 3,044>1,96 yang berarti variabel kualitas kehidupan kerja berpengaruh positif dan signifikan terhadap kinerja karyawan di Bukit Cili Rafting Karangasem dengan komitmen organisasional sebagai variable mediasi parsial, maka hipotesis keempat diterima. Hasil penelitian ini sejalan dengan Hasil penelitian yang dilakukan oleh Ramadhoan (2015) menyatakan Kualitas kualitas kehidupan kerja terhadap kinerja karyawan akan semakin berpengaruh besar atau positif jika memasukan variable komitmen organisasional sebagai variable mediasi, dengan kata lain jika ingin meningkatkan kinerja melalui kualitas kualitas kehidupan kerja maka harus menciptakan atau meningkatkan komitmen organisasional terlebih dahulu sebagai peratara $q w l$ terhadap kinerja karyawan. Asharini \& Irham (2018) komitmen organisasional terbukti sebagai variable mediasi antara kualitas kualitas kehidupan kerja terhadap kinerja karyawan. Ahadi et al. (2018) Komitmen organisasional memediasi pengaruh kualitas kehidupan kerja terhadap kinerja karyawan. kualitas kehidupan kerja berpengaruh positif dan signifikan terhadap kinerja karyawan yang di mediasi oleh komitmen organisasional (Giarto, 2018).

Implkasi teoritis dari hasil penelitin ini memberikan bukti pada pengembangan ilmu perilaku keorganisasian dan sumber daya manusia khususnya mengenai kualitas kehidupan kerja, komitmen organisasional dan kinerja karyawan. Selain itu hasil penelitian ini secara praktis dapat menjadi salah satu acuan bagi peneliti lainnnya yang ingin meneliti mengenai kualitas kehidupan kerja, komitmen organisasional dan kinerja karyawan. Secara teoritis penelitian ini juga memberikan pemahaman bahwa kualitas kehidupan kerja dan komitmen organisasional secara nyata dapat meningkatkan kinerja karyawan, ketika kualitas kehidupan kerja yang diperoleh oleh karyawan tinggi maka dapat meningkatkan komitmen organisasional menjadi semakin tinggi, sehingga berpotensi meningkatkan kinerja karyawan.

\section{SIMPULAN}

Kualitas kehidupan kerja berpengaruh positif dan signifikan terhadap kinerja karyawan Bukit Cili Rafting. Hal ini berarti semakin tingginya kualitas kehidupan kerja maka kinerja karyawan akan meningkat pula. Kualitas kehidupan kerja berpengaruh positif dan signifikan terhadap komitmen organisasional Bukit Cili Rafting. Hal ini berarti semakin tingginya kualitas kehidupan kerja maka komitmen organisasional semakin tinggi. Komitmen organisasional berpengaruh positif dan signifikan terhadap kinerja karyawan Bukit Cili Rafting. Hal ini berarti semakin tingginya komitmen organisasional 
maka kinerja karyawan semakin meningkat. Komitmen organisasional mediasi secara parsial pengaruh kualitas kehidupan kerja terhadap kinerja karyawan Bukit Cili Rafting. Kualitas kehidupan kerja akan semakin berpengaruh positif dan signifikan terhadap kinerja karyawan jika memasukan variable komitmen organisasional sebagai variable mediasi.

Bukit Cili Rafting sebaiknya memperhatikan pengembangan karir setiap karyawan, agar mutu karyawan semakin meningkat untuk mencapai kinerja yang maksimal. Hal ini didasarkan pada jawaban responden yang memiliki nilai rata-rata terendah adalah pernyataan "organisasi selalu memberikan pengembangan karir bagi setiap karyawan" yang memperoleh nilai rata-rata sebesar 3,33 yang masuk kriteria cukup baik. Bukit Cili Rafting sebaiknya memberikan perhatian lebih terhadap karyawan guna meningkatkan kesetiaan setiap karyawan terhadap organisasi dalam hal menjaga komitmen organisasional. Hal ini didasarkan pada jawaban responden yang memiliki nilai rata-rata terendah adalah pernyataan "saya tidak tertarik pada tawaran pekerjaan dari organisasi lain yang mungkin lebih baik dari organisasi ini" yang memperoleh nilai rata-rata sebesar 3,29 yang masuk kriteria cukup baik. Bukit Cili Rafting sebaiknya memberikan perhatian lebih baik dari segi pelatihan guna meningkatkan kompetensi setiap anggota organisasi supaya nantinya dapat mengerjakan pekerjaan dengan sedikit instruksi dari atasan. Hal ini berdasarkan pada jawaban responden yang memiliki nilai rata-rata terendah yaitu pernyataan "saya dapat mengerjakan pekerjaan dengan baik tanpa banyak instruksi dari atasan" mampu menyelesaikan pekerjaan dengan tepat waktu" yang memperoleh nilai rata-rata sebesar 3,33 yang masuk kriteria cukup baik.

\section{REFERENSI}

Ahadi, A., Ibrahim, Q., Sullaida, N., \& Novita, Y. (2018). Organizational Commitment As An Intervening Variable, The Influence Of The Job Satisfaction, Organizational Citizenship Behavior, Quality Of Work Life , Against The Employee Performance : A Case Study: In The Regional Public Service Women's And Children'. Indonesian Journal of Educational Review, 5(2), 39-48.

Amirul, A., Musadieq, M. A., \& Mukzam, M. . (2017). Pengaruh Komitmen Organisasional Terhadap Kinerja (Studi Pada Karyawan PT PELINDO Surabaya). Jurnal Administrasi Bisnis (JAB), 47(2), 33-38.

Archita, K. D. N. P. A., \& Sintaasih, D. K. (2016). Organizational Citizenship Behavior, Kepemimpinan Transaksional, Dan Komitmen Organisasional: Pengaruhnya Terhadap Kinerja Karyawan. E-Jurnal Manajemen Unud, 5(11), 7418-7445.

Asharini, N. A., \& Irham, S. H. (2018). The Impact of Quality of Work Life and Job Satisfaction on Employee Performance of PT. Madubaru PG-PS Madukismo. IOSR Journal of Businees an Management, 29(1), 146-149. 
Bandula, P. . M. K. . U., \& Jayatilake, L. V. K. (2016). Impact of Employee Commitment on Job Performance : Based on Leasing Companies in Sri Lanka. International Journal of Arts and Commerce, 5(8), 8-22.

Basalama, M. Z. S., \& Piartrini, P. . (2019). Pengaruh Servant Leadership Dan Komitmen Organisasional Terhadap Kinerja Karyawan Bagian Dana Bank Sultra Kendari. E-Jurnal Manajemen Unud, 8(10), 5984-6001.

Berberoglu, A., \& Secim, H. (2015). Organizational Commitment and Perceived Organizational Performance Among Health Care Professionals: Empirical Evidence From a Private Hospital in Northern Cyprus . Journal of Economics and Behavioral Studies, 7(1), 64-71.

Bhatnagar, T., \& Soni, H. (2015). Impact of quality of work life on job satisfaction of school teachers in Udaipur city. IOSR Journal of Business and Management, 17(3), 10-14.

Fu, W., \& Deshpande, S. P. (2015). The Impact of Caring Climate, Job Satisfaction, and Organizational Commitment on Job Performance of Employees in a China's Insurance Company. IOSR Journal of Business and Management, 1(1), 339-349.

Giarto, S. . (2018). Effects of Quality of Work Life on Employee Performance with Job Satisfaction and Organizational Commitment as Mediating Variables at PT. Solusky Yogyakarta. IOSR Journal of Businees an Management, 1(1), 230.

Hogantara, A., \& Sintaasih, D. K. (2015). Pengaruh Tingkat Kesejahteraan, Kepuasan Kerja, Dan Komitmen Organisasi Terhadap Kinerja Karyawan Aroma Spa, Sanur Denpasar. E-Jurnal Manajemen Unud, 4(2), 336-354.

Indrasari, M., Momin, M. M., Nur, S., Newcombe, P., \& Permana, S. (2018). Influence of Motivation and Quality of Work Life on The Performance of Employees. Economic and Business Review, 4(1), 42-48.

Irawati, S. A. (2015). Pengaruh Kualitas Kehidupan Kerja Terhadap Kinerja Pegawai Dinas Perindustrian dan Perdagangan Kabupaten Sampang. Jurnal Neo-Bis, 9(2), $41-52$.

Karno, P., \& Indrawati, A. D. (2016). Pengaruh iklim organisasi dan kualitas kehidupan kerja terhadap kinerja pegawai dinas sosial provinsi bali. E-Jurnal Manajemen Unud, 5(12), 7785-7809.

Nathania, Y. (2018). Pengaruh Budaya Organisasi Dan Komitmen Organisasional Terhadap Kinerja Karyawan Pada Warunk Upnormal Surabay. Jurnal Administrasi Bisnis, 6(1), 1-9. 
Planer, D. G. (2019). The Relationship between Organizational Commitment and Organizational Citizenship Behaviors in the Public and Private Sectors. Sustainability (Switzerland), 6(6), 1-20. https://doi.org/10.5897/ajbm11.1216

Rabenu, L. C.-H., \& Rabenu, E. (2018). The New Era Workplace Relationships: Is Social Exchange Theory Still Relevant? Industrial and Organizational Psychology, 11(3), https://doi.org/https://doi.org/10.1017/iop.2018.5

Rai, R., \& Tripathi, S. (2015). A Study on QWL and its effects on Job Performance. Journal of Management Sciences and Technology, 2(2), 33-42.

Ramadhoan. (2015). Kualitas Kehidupan Kerja Terhadap Kinerja Karyawan Melalui Komitmen Organisasi dan Kepuasan Kerjasebagai Variabel Antara (Intervening Variable). Jurnal Administrasi Bisnis, 13(2), 199-217.

Sari, N. P. R., Bendesa, I. K. G., \& Antara, M. (2019). The Influence of Quality of Work Life on Employees' Performance with Job Satisfaction and Work Motivation as Intervening Variables in Star-Rated Hotels in Ubud Tourism Area of Bali. Journal of Tourism and Hospitality Management, 7(1), 74-83. https://doi.org/10.15640/jthm.v7n1a8

Selda, T. A. (2015). Impact of the Quality of Work-Life on Organizational Commitment: A Comparative Study on Academicians Working for State and Foundation. ISGUC The Journal of Industrial Relations and Human Resources, 17(2), 45-75. https://doi.org/10.4026/1303-2860.2015.0278.x

Tripathy, L. K. (2017). Impact of Quality of Work Life on Job Performance. International Journal of Business Marketing and Management, 2(10), 11-14. Retrieved from www.ijbmm.com

Velayudhan, T. . M., \& Yameni, M. . (2017). Quality of Work Life - A Study. IOP Conference Series.: Material Science and Engineering, 36(1), 10-12. https://doi.org/10.1088/1757-899X

Vipraprastha, T., Sudja, I. N., \& Anik, Y. (2018). The Effect Of Transformational Leadership and Organizational Commitment to Employee Performance with Citizenship Organization (OCB) Behavior As Intervening Variables (At PT Sarana Arga Gemeh Amerta in Denpasar City). International Journal of Science and Research, 9(2), 1-10.

Wahyudi, K. C. I., \& Indrawati, A. D. (2017). Pengaruh Kepemimpinan Transformasional Dan Komitmen Organisasi Terhadap Kinerja Pegawai Dinas Sosial Provinsi Bali. E-Jurnal Manajemen Unud, 6(9), 4887-4918. 
I Putu Widnyana Putra, Kualitas Kehidupan Kerja...

Yuhista, A., Ariana, N., \& Arismayanti, N. K. (2017). Analisis pengaruh kualitas kehidupan kerja quality of work life (qwl) terhadap kinerja karyawan pada cottage di pantai tanjung setia pesisir barat lampung. Jurnal Kepariwisataan Dan Hospitalitas Universitas Udayana, 1(2), 74-92. 